\section{Miembro Superior}

Claviculectomía total como procedimiento de rescate.

Reporte de un caso y revisión bibliográfica

124

Descompresión ósea metafisaria del radio distal para estadios tempranos de la enfermedad de Kienböck. Seguimiento mínimo de 10 años

25

Injerto óseo vascularizado pediculado del radio distal para tratar la seudoartrosis recalcitrante del cúbito

Fracturas de falanges tratadas con placas

de osteosíntesis. Resultados a corto plazo

Colgajo paraescapular en pérdidas postraumáticas de tejidos blandos de las extremidades

Versatilidad del colgajo libre anterolateral de muslo en la reconstrucción de defectos de cobertura en los miembros superiores e inferiores

167

\section{MIEMbRo INFERIOR}

Uso de copas de tantalio trabecular para la reconstrucción acetabular compleja.

Resultados de una serie de 42 casos $\mathrm{y}$ un seguimiento promedio de tres años

Artroplastia de cadera luego de una osteosíntesis fallida en fracturas laterales de cadera

Indicación y resultados de la prótesis con estabilidad aumentada en la artroplastia primaria de rodilla

Fracturas atípicas de fémur proximal asociadas al uso prolongado de bifosfonatos

152

Rescate de osteosíntesis intertrocantéricas y subtrocantéricas fallidas con un reemplazo articular. Técnica y resultados de una serie de 61 casos

Estudio histopatológico en rotura aguda del ligamento cruzado anterior de rodilla

Uso tópico de ácido tranexámico en el reemplazo total de rodilla primario

Trasplante osteocondral autólogo para tratar lesiones osteocondrales de la rodilla: evaluación de 62 pacientes con un seguimiento promedio de ocho años
Resultados funcionales y complicaciones de fracturas de platillo tibial por traumatismos de alta energía

Tratamiento de las fracturas complejas de platillo tibial con compromiso de la tuberosidad anterior de la tibia

Luxación traumática aguda de la articulación tibioperonea proximal. Reporte de un caso y revisión bibliográfica

Roturas del tendón de Aquiles operadas con técnica percutánea: resultados quirúrgicos y complicaciones posoperatorias

Análisis de la displasia epifisaria hemimélica (enfermedad de Trevor) de tobillo

Presentación inusual de una fractura-luxación peritalar

Rotura traumática del extensor propio del hallux en la inserción distal. Reporte de un caso

Resultados de la cirugía mínimamente invasiva y cirugía abierta tipo scarf para la corrección del hallux valgus moderado y severo.

Estudio observacional retrospectivo

12 Colgajo paraescapular en pérdidas postraumáticas de tejidos blandos de las extremidades

Versatilidad del colgajo libre anterolateral de muslo en la reconstrucción de defectos de cobertura en los miembros superiores e inferiores

\section{Columna}

Colgajo de recto anterior del abdomen para el tratamiento de los defectos de cobertura lumbosacros

Funcionalidad y calidad de vida luego de la cirugía de escoliosis neuromuscular

Aloinjerto fresco congelado en cirugía de columna lumbar: ¿Aumenta la tasa de infección?

Artrodesis intersomática lateral de columna lumbar. Técnica quirúrgica y conceptos actuales 


\section{TUMORES}

Tumor de células gigantes espinal en niños.

Reporte de dos casos

197

\section{ORTOPEDIA INFANTIL}

Fractura por estrés del cuello del fémur en una niña hiperactiva tratada con metilfenidato.

Reporte de un caso

Enclavado endomedular elástico para el

tratamiento de refracturas de antebrazo en niños

\section{Temas Generales}

Anastomosis entre vasos ilíacos y obturadores en la región retropúbica: estudio en cadáveres

Informe sobre la radio-exposición en el personal quirúrgico de Ortopedia y Traumatología. Principios, marco legal y análisis situacional en la Argentina

Síndrome SAPHO. Presentación de un caso clínico

Síndrome de Grebe. Reporte de un caso

Osteomielitis crónica recurrente multifocal.

Reporte de tres casos y revisión bibliográfica

Tratamiento de la osteomielitis asociada a úlceras alrededor de la pelvis
283

248
Instrucción Ortopédica de Posgrado IMÁGENES

97 Síndrome de Parsonage-Turner

2 y 54

Hiperostosis esquelética idiopática difusa

71 y 131

Trombosis de la vena plantar lateral

147 y 214

45 Micetoma (pie de Madura)

229 y 317

\section{Editoriales}

242

A los socios de la Asociación Argentina

de Ortopedia y Traumatología

Cirugía percutánea del pie:

¿hacia dónde debemos ir?

Residencias y algo más...

Comité de Morbi-Mortalidad de la Asociación

210 Argentina de Ortopedia y Traumatología

\section{Obituarios}

50 Dr. Javier Maquirriain

Dr. Santiago Fazzini

321 